\title{
Resistome and a Novel bla NDM-1 -Harboring Plasmid of an Acinetobacter haemolyticus Strain from a Children's Hospital in Puebla, Mexico
}

\author{
Elena Bello-López, ${ }^{1}$ Semiramis Castro-Jaimes, ${ }^{2}$ Miguel Ángel Cevallos, ${ }^{2}$ Rosa del Carmen Rocha-Gracia, \\ Miguel Castañeda-Lucio,, Yolanda Sáenz, ${ }^{3}$ Carmen Torres, ${ }^{4}$ Zita Gutiérrez-Cazares, ${ }^{5}$ \\ Ygnacio Martínez-Laguna, and Patricia Lozano-Zarain ${ }^{1}$
}

\begin{abstract}
Acinetobacter calcoaceticus-baumannii complex isolates have been frequently associated with hospital and community infections, with A. baumannii being the most common. Other Acinetobacter spp. not belonging to this complex also cause infections in hospital settings, and the incidence has increased over the past few years. Some species of the Acinetobacter genus possess a great diversity of antibiotic resistance mechanisms, such as efflux pumps, porins, and resistance genes that can be acquired and disseminated by mobilizable genetic elements. By means of whole-genome sequencing, we describe in the clinical Acinetobacter haemolyticus strain AN54 different mechanisms of resistance that involve bla $a_{\mathrm{OXA}-265}, b l a_{\mathrm{NDM}-1}, a p h A 6, a a c\left(6^{\prime}\right)-I g$, and a resistance-nodulation-cell division-type efflux pump. This strain carries six plasmids, of which the plasmid pAhaeAN54e contains bla $a_{\text {NDM-1 }}$ in a Tn125-like transposon that is truncated at the $3^{\prime}$ end. This strain also has an insertion sequence IS91 and seven genes encoding hypothetical proteins. The pAhaeAN54e plasmid is nontypable and different from other plasmids carrying bla $_{\mathrm{NDM}-1}$ that have been reported in Mexico and other countries. The presence of these kinds of plasmids in an opportunistic pathogen such as A. haemolyticus highlights the role that these plasmids play in the dissemination of antibiotic resistance genes, especially against carbapenems, in Mexican hospitals.
\end{abstract}

Keywords: A. haemolyticus, plasmid, NDM-1, antibiotic resistance

\section{Introduction}

$\mathbf{T}$ HE GENUS ACINETOBACTER INCLUDES a group of bacteria that can be isolated from a wide variety of environmental sources, including soil and water. However, some of them have become important nosocomial pathogens, such as those included within the Acinetobacter calcoaceticusbaumannii complex. Members of this genus have been associated with severe nosocomial and community infections with high mortality rates. Nevertheless, isolates of other non-baumannii spp. have gained medical relevance because of their increased frequency in recent years, for example, Acinetobacter haemolyticus, Acinetobacter lwoffii, Acinetobacter ursingii, Acinetobacter parvus, and Acinetobacter junii. ${ }^{1-3}$

Acinetobacter spp. have developed resistance to multiple classes of antimicrobial agents, including broad-spectrum cephalosporins, carbapenems, fluoroquinolones, and aminoglycosides. This resistance is due to multiple mechanisms, such as resistance-nodulation-cell division (RND)-type efflux pumps, CarO porin, and resistance genes. In addition, the ability of Acinetobacter spp. to acquire mobilizable

\footnotetext{
${ }^{1}$ Centro de Investigaciones de Ciencias Microbiológicas, Instituto de Ciencias, Benemérita Universidad Autónoma de Puebla, Puebla, México.

${ }^{2}$ Programa de Genómica Evolutiva, Centro de Ciencias Genómicas, Universidad Nacional Autónoma de México, Cuernavaca, México.

${ }^{3}$ Área de Microbiología Molecular, Centro de Investigación Biomédica de La Rioja (CIBIR), Logroño, España.

${ }^{4}$ Área Bioquímica y Biología Molecular, Universidad de La Rioja, Logroño, España.

${ }^{5}$ Hospital para el Niño Poblano, Puebla, México.

Part of these results were presented at the XXIV Latin-American Congress of Microbiology, Santiago, Chile, November 13-16, 2018.

(C) Elena Bello-López et al., 2019; Published by Mary Ann Liebert, Inc. This Open Access article is distributed under the terms of the Creative Commons License (http://creativecommons.org/licenses/by/4.0), which permits unrestricted use, distribution, and reproduction in any medium, provided the original work is properly cited.
} 
elements that carry antibiotic resistance genes increases the resistance dissemination. ${ }^{4-6}$ In particular, bla $a_{\mathrm{NDM}-1}$, which encodes the New Delhi Metallo- $\beta$-lactamase-1 (NDM-1), hydrolyzes a broad spectrum of $\beta$-lactam antibiotics, including carbapenems, and is among the most worrisome resistance determinants that have spread around the world, severely complicating the treatment of nosocomial infections. ${ }^{7-10}$ In Latin America, its presence has been reported in Enterobacteriaceae isolates such as Klebsiella pneumoniae, Escherichia coli, and Providencia rettgeri, ${ }^{11-13}$ and in nonfermentative bacilli, such as A. baumannii, Acinetobacter pittii, Acinetobacter bereziniae, and A. haemolyticus. ${ }^{14-17}$ In this work, we report the presence of diverse antibiotic resistance genes in a strain of $A$. haemolyticus obtained from a Mexican pediatric patient and the characterization of the complete plasmid carrying $b l a_{\mathrm{NDM}-1}$ isolated from this strain.

\section{Materials and Methods}

\section{Bacterial isolation}

Acinetobacter haemolyticus AN54 was recovered from peritoneal dialysis fluid culture from a 12-year-old male patient who had been admitted to the hospital for end-stage renal disease in February 2016. The patient was previously treated with ceftriaxone (CRO) and trimethoprimsulfamethoxazole (SXT). The isolate was identified with the VITEK 2 system (bioMérieux) and molecular typing by sequencing of the $r p o B$ gene. ${ }^{18,19}$

\section{Antimicrobial susceptibility testing}

An antimicrobial susceptibility test was performed by using the agar disk diffusion method according to the Clinical and Laboratory Standards Institute guidelines. ${ }^{20}$ The following antimicrobials were tested: piperacillin (PIP), ticarcillin (TIC), ampicillin/sulbactam, piperacillin/ tazobactam, ticarcillin-clavulanic acid (TIM), ceftazidime (CAZ), cefepime (FEP), cefotaxime (CTX), CRO, imipenem (IPM), meropenem (MEM), gentamicin, amikacin (AN), tetracycline, ciprofloxacin, levofloxacin, and SXT. The minimal inhibitory concentration (MIC) for CTX, CAZ, FEP, MEM, IPM, and AN was determined by the agar dilution method. ${ }^{20}$ Metallo- $\beta$-lactamase (MBL) detection was performed by IPM and MEM disks supplemented with $10 \mu \mathrm{L}$ of $0.5 \mathrm{M}$ ethylenediaminetetraacetic acid. ${ }^{21}$

\section{Test of the activity of the efflux pump in antibiotic resistance}

The activity of the efflux pump was evaluated by using phenylalanine-arginine $\beta$-naphthylamide (Sigma-Aldrich) as an efflux pump inhibitor (EPI). The test was performed as follows: MICs for AN, CTX, and MEM were determined by the agar dilution method in the presence and absence of EPI $(25 \mathrm{mg} / \mathrm{L})$. A twofold or greater decrease in MIC in the presence of EPI was considered indicative of a role of RND-type efflux pumps in the resistance to the antibiotics tested. Test veracity was checked by using the strain Acinetobacter haemolyticus HNP11 as a positive control. To evaluate the effect of EPI on bacterial growth, all bacteria were cultured in Mueller-Hinton broth with and without EPI $(25 \mathrm{mg} / \mathrm{L}){ }^{22}$

\section{Whole-genome sequencing and data analysis}

A high-quality draft genome sequence from isolate AN54 was obtained by using an Illumina MiSeq platform $(2 \times 300$ paired-end reads) (IBT-UNAM) and one SMRT cell of PacBio RS II system (Yale Center for Genome Analysis). With data obtained from both platforms, a hybrid assembly was performed with the Unicycler assembler version 0.4.1. ${ }^{23}$ and SPAdes version 3.11.1. ${ }^{24}$ ResFinder $2.1^{25}$ was used to identify and determine the location of antibiotic resistance genes. MAUVE version 20150226, ${ }^{26}$ CLC Sequence Viewer 8.0 and BLAST were used to align and compare sequences. EASYFIG 2.2.2 was used to draw figures. ${ }^{27}$

\section{Pulsed-field gel electrophoresis and Southern blot}

The S1 nuclease-pulsed-field gel electrophoresis (PFGE) method was carried out to determine the plasmids number by using the Escherichia coli strain NCTC 50192 as a reference. To detect the resistance gene in the plasmid, the PFGE gel was transferred to a nylon membrane (Hybond-N; GE Healthcare Life Sciences), and hybridization was performed with the Dig-High Prime DNA Labeling and Detection Starter Kit II (Roche).

\section{Conjugation assays}

Conjugation assays from AN54 to recipient strains Escherichia coli C600 (rifampicin resistant) and Escherichia coli DH5 $\alpha$ (nalidixic acid resistant) were performed. Mueller-Hinton agar plates (BD Bioxon) supplemented with rifampicin $(100 \mu \mathrm{g} / \mathrm{mL})$ or nalidixic acid $(32 \mu \mathrm{g} / \mathrm{mL})$ containing $\mathrm{AN}(32 \mu \mathrm{g} / \mathrm{mL})$ and MEM $(8 \mu \mathrm{g} / \mathrm{mL})$ were used for the selection of transconjugant strains.

Nucleotide sequence accession numbers. Draft genome and plasmid sequences of the AN54 strain were deposited in the GenBank database, with accession numbers CP041224.1 to CP041229.1.

\section{Results}

In this work, we report the identification of an Acinetobacter haemolyticus (AN54) strain resistant to carbapenems, which was isolated from peritoneal dialysis fluid. This strain was initially identified as Acinetobacter spp. by a VITEK 2 System and subsequently reclassified as A. haemolyticus by analysis of the $r p o B$ gene. The AN54 strain exhibited resistance to $\mathrm{AN}$, and to the broad-spectrum $\beta$-lactams antibiotics, except for TIM. The $b l a_{\mathrm{NDM}-1}$ and $b l a_{\mathrm{OXA}-265}$ were previously detected by PCR and sequencing. A twofold decrease in the MIC for AN and no change in the MICs for CTX and MEM in the presence of EPI were observed. In addition, the phenotypic test to detect MBL production was positive (Table 1).

Plasmid DNA extraction revealed that the AN54 isolate carries six different bands. Southern blot hybridization indicated that $b l a_{\mathrm{NDM}-1}$ was present in one of the plasmids (Fig. 1).

Whole-genome sequencing analysis revealed that AN54 possess a chromosome with a size of $\sim 3.61 \mathrm{Mbp}$, and we obtained the complete sequence of four plasmids named 


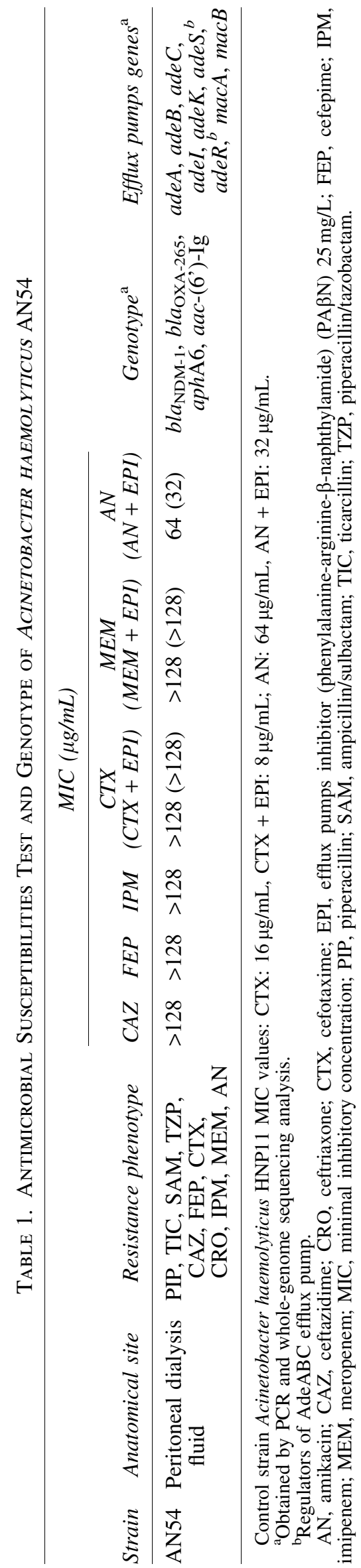

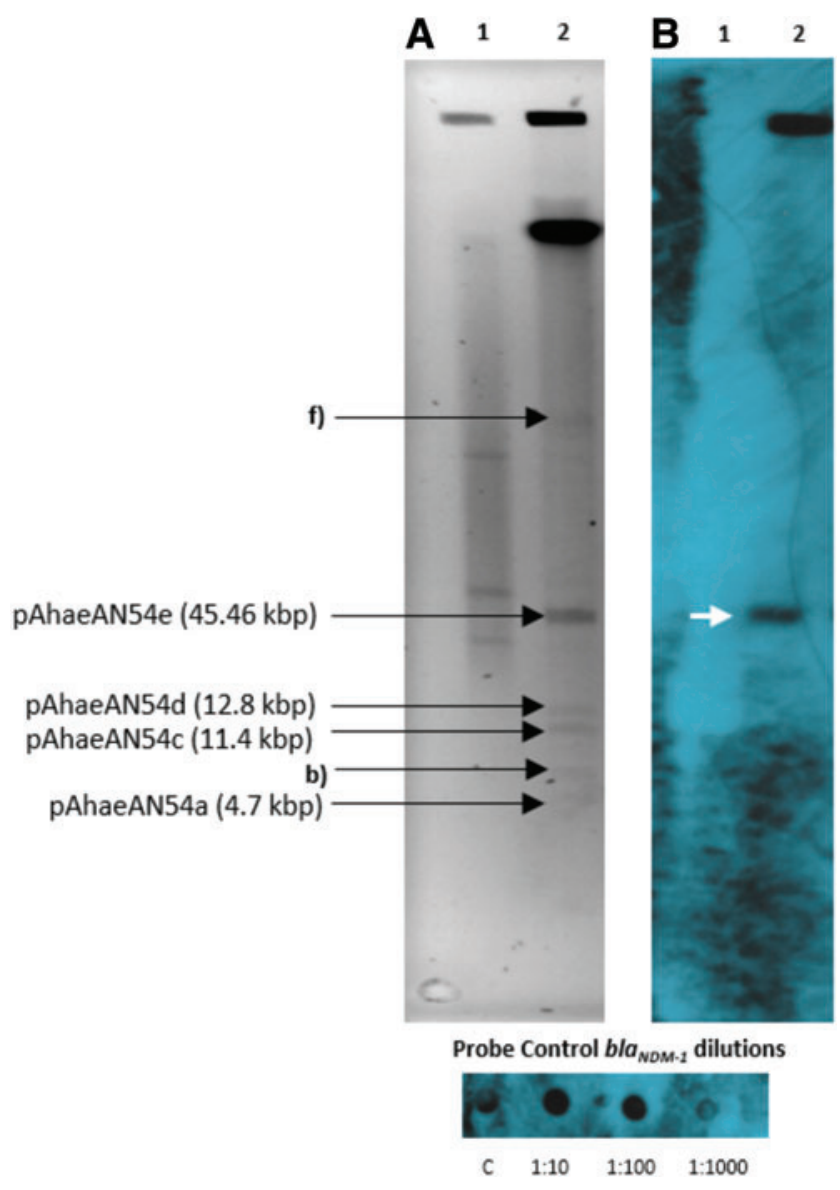

FIG. 1. (A) PFGE-S1 gel showing the plasmids of Acinetobacter haemolyticus AN54 strain, Line 1: Control strain Escherichia coli NCTC 50192, Line 2: AN54. (B) Hybridization autoradiography with the $b l a_{\mathrm{NDM}-1}$ probe (DIG-High Prime DNA Labeling and Detection Starter Kit II, Roche). The white arrow indicates that $b l a_{\mathrm{NDM}-1}$ was detected in the plasmid pAhaeAN54e. The plasmid sizes were determined by WGS. PFGE, pulsed-field gel electrophoresis. Color images are available online.

pAhaeAN54a (4.7 kbp), pAhaeAN54c (11.4 kbp), and pAhaeAN54d $(12.8 \mathrm{kbp})$ that do not carry antimicrobial resistance genes, and pAhaeAN54e (45.46 kbp) that carries $b l a_{\mathrm{NDM}-1}$ and $a p h A 6$. In the chromosome, we detected the presence of bla $a_{\mathrm{OXA}-265}$ and the aminoglycoside-modifying enzyme-encoding gene $a a c\left(6^{\prime}\right)-I g$. In addition, genes for efflux pumps and their regulators that mediate multidrug resistance were found:, adeA, adeB, adeC, adeI, adeK, adeR, adeS, macA, and macB, as well as heavy metal resistance genes $c z c A$ and $\operatorname{arsH}$.

The $b l a_{\mathrm{NDM}-1}$ was located in the $45.46 \mathrm{kbp}$ plasmid, which we named pAhaeAN54e. This plasmid has a $41 \%$ guanine-cytosine content and 53 open reading frames. Sixteen of these genes are related to plasmid maintenance and transfer functions (plasmid backbone) and include the plasmid-partitioning genes parA and parB, and transfer genes $\operatorname{traA}, \operatorname{traC}$, and $\operatorname{traD}$, as well as some genes of the type IV secretion system (T4SS). Twelve genes of this plasmid are located within the composite transposon carrying $b l a_{\mathrm{NDM}-1}$, and the remaining genes encode 25 hypothetical 
proteins. Conjugation assays were performed to test the transferability of this plasmid; however, no transconjugants were obtained under the tested conditions.

Plasmid pAhaeAN54e has 99\% nucleotide identity, with $100 \%$ coverage, to plasmids pNDM-BJ02 (accession no. JQ060896.1) and pNDM-BJ01 (accession no. JQ001791.1) of $A$. lwoffii. ${ }^{28}$ Figure 2 shows the detected differences, especially the insertion of seven genes encoding hypothetical proteins along the T4SS gene cluster, near the parA and traA genes, and a deletion of a hypothetical protein upstream of traC. The pAhaeAN54e plasmid also has a truncated composite transposon that is similar to transposon Tn125. Both these transposons consist of the ISAbal4 insertion sequence and the $a p h A 6, b l a_{\mathrm{NDM}-1}, b l e$, and $\operatorname{trpF}$ genes, but in contrast to Tn125, the truncated transposon of strain AN54 has only one copy of the insertion sequence ISAba125. The structure of the truncated transposon is similar to that found in plasmid pNDM-BJ02 and to the partially sequenced plasmids pABC7926 (accession no. JQ080305.2) and pNDM-69122 (accession no. LN611576.1) of A. haemolyticus (Fig. 3). ${ }^{29,30}$

Plasmid pAhaeAN54e contains an IS91 family transposase, which is $330 \mathrm{bp}$ larger than the insE transposase gene carried on the pNDM-BJ02 and pNDM-BJ01 plasmids in $A$. lwoffii. In addition, pAhaeAN54e has an insertion of two genes encoding hypothetical proteins downstream of IS91 and one more that is adjacent to the recombinase gene.

Interestingly, plasmid pAhaeAN54e has 99\% identity with more than $73 \%$ of coverage with the $P$. rettgeri plasmid p06-1619-NDM (accession no. KX832928.1) reported in Mexico (Fig. 4). ${ }^{31}$ These plasmids share 33 genes, including $\operatorname{traA}, \operatorname{traC}$, traD, and genes from the type IV secretion system. Plasmid p06-1619-NDM also has a Tn125-like element.

\section{Discussion}

A. baumannii is one of the principal etiological agents causing nosocomial infections in Mexico and the rest of the world. $^{32-34}$ In Mexican hospitals, there are a few reports of carbapenem-resistant Acinetobacter isolates that are not included in the A. calcoaceticus-baumannii complex, ${ }^{17}$ possibly because the molecular typing of these species is not routinely implemented in Mexican hospitals. In this work, we studied the resistome of an A. haemolyticus strain resistant to carbapenems. The strain carries different resistance mechanisms, such as bla $a_{\text {OXA-265 }}$, which is a member of the bla $a_{\mathrm{OXA}-214}$-like family on the A. haemolyticus chromosome. ${ }^{35}$ The strain also harbors aminoglycosidemodifying enzyme genes, such as aac(6')- Ig, which is responsible for AN resistance and belongs to the AAC(6')-I aminoglycoside $\mathrm{N}$-acetyltransferase family reported in $\mathrm{Aci}$ netobacter spp., ${ }^{36,37}$ and aphA6, which confers resistance to $\mathrm{AN}$ and is associated with the presence of $b l a_{\mathrm{NDM}-1}$ in a plasmid from this strain, as has been reported in another study. $^{38}$

Another antibiotic resistance mechanism studied in A. baumannii is the use of efflux pumps, mainly the RND family of efflux pumps, such as the AdeABC and AdeIJK systems, which are located on the bacterial chromosome. This family exhibits a wide substrate range that includes dyes, biocides, detergents, and antiseptics; however, its presence has been little studied in non-baumannii spp. ${ }^{39}$ The overexpression of this system was shown to be responsible for decreasing susceptibility to a broad spectrum of antimicrobials, such as aminoglycosides, tetracyclines, erythromycin, chloramphenicol, trimethoprim, fluoroquinolones, some $\beta$-lactams, and ethidium bromide, and has recently also been associated with tigecycline. ${ }^{40}$ The genes that encode the AdeABC efflux pump are organized in an operon $(a d e A B C)$. There are two regulatory genes, adeS and $a d e R$, and their products are closely related to proteins of the two-component regulatory system. These genes regulate efflux pump expression in response to cellular environment stimuli (antibiotics). This type of expression is called inductive. $^{41}$

AdeIJK encoded by the adeIJK operon is the second RND efflux system described in A. baumannii, ${ }^{42}$ which contributes to the resistance to $\beta$-lactams, such as TIC, cephalosporins, aztreonam, fluoroquinolones, tetracyclines, tigecycline, lincosamides, rifampicin, and chloramphenicol; however, aminoglycosides are not substrates for this pump. ${ }^{43}$ The Acinetobacter haemolyticus AN54 strain contains homologues of the regulator proteins AdeS and AdeR and the efflux pump components AdeA, AdeB and AdeC with the Acinetobacter baumannii AYE strain, these proteins share an amino acid identity of $72 \%, 85 \%, 86 \%, 92 \%$ and $77 \%$ respectively, to the corresponding proteins. In addition, homologues of AdeI and AdeK proteins with $82 \%$ and $89 \%$ identity with Acinetobacter baumannii AYE were also found. However, the AdeJ subunit in strain AN54 was not located.

In this work, EPI was used to evaluate the role of the efflux pump in antibiotic resistance. The results obtained indicate that the efflux pump only participates in conferring resistance to $\mathrm{AN}$, as shown by a twofold decrease in the MIC (from 64 to $32 \mu \mathrm{g} / \mathrm{mL}$ ). The strain did not show a decrease in the MICs of CTX and MEM, possibly due to the presence of $b l a_{\mathrm{NDM}-1} .^{6}$

The presence of $b l a_{\mathrm{NDM}-1}$ in a non-baumannii spp. of environmental origin such as A. haemolyticus is medically and epidemiologically relevant. This is especially true considering the lack of successful treatment for patients with some underlying diseases and the ease of $b l a_{\mathrm{NDM}-1}$ dissemination through complex recombination events mediated by insertion sequences, transposons, and plasmids, as reported in previous works. ${ }^{31,44,45}$

The Acinetobacter haemolyticus AN54 strain harbors bla $_{\text {NDM-1 }}$ within a Tn125-like transposon in a plasmid highly similar to pNDM-BJ02 of A. lwoffii, which has been previously reported in China. ${ }^{28}$ The backbone of the plasmids carrying bla NDM-1 $_{1}$ between Acinetobacter spp. is relatively conserved; however, one difference found in our plasmid is the presence of IS91. This gene is designated as ISCR, and one of its functions is the mobilization of additional sequences upstream of the transposase gene. ${ }^{46,47}$ The second difference is the insertion of seven genes encoding hypothetical proteins in the putative conjugation region; the function of these proteins is yet unknown. Currently, there are no methodologies to characterize this kind of replicon, due to the absence of a typical Rep protein, such as the one presented by Enterobacteriaceae plasmids, indicating that these plasmids possess an uncharacterized replication system; therefore, additional studies are needed. No transconjugants were obtained under the tested conditions. However, we cannot exclude other alternative mechanisms of plasmid 


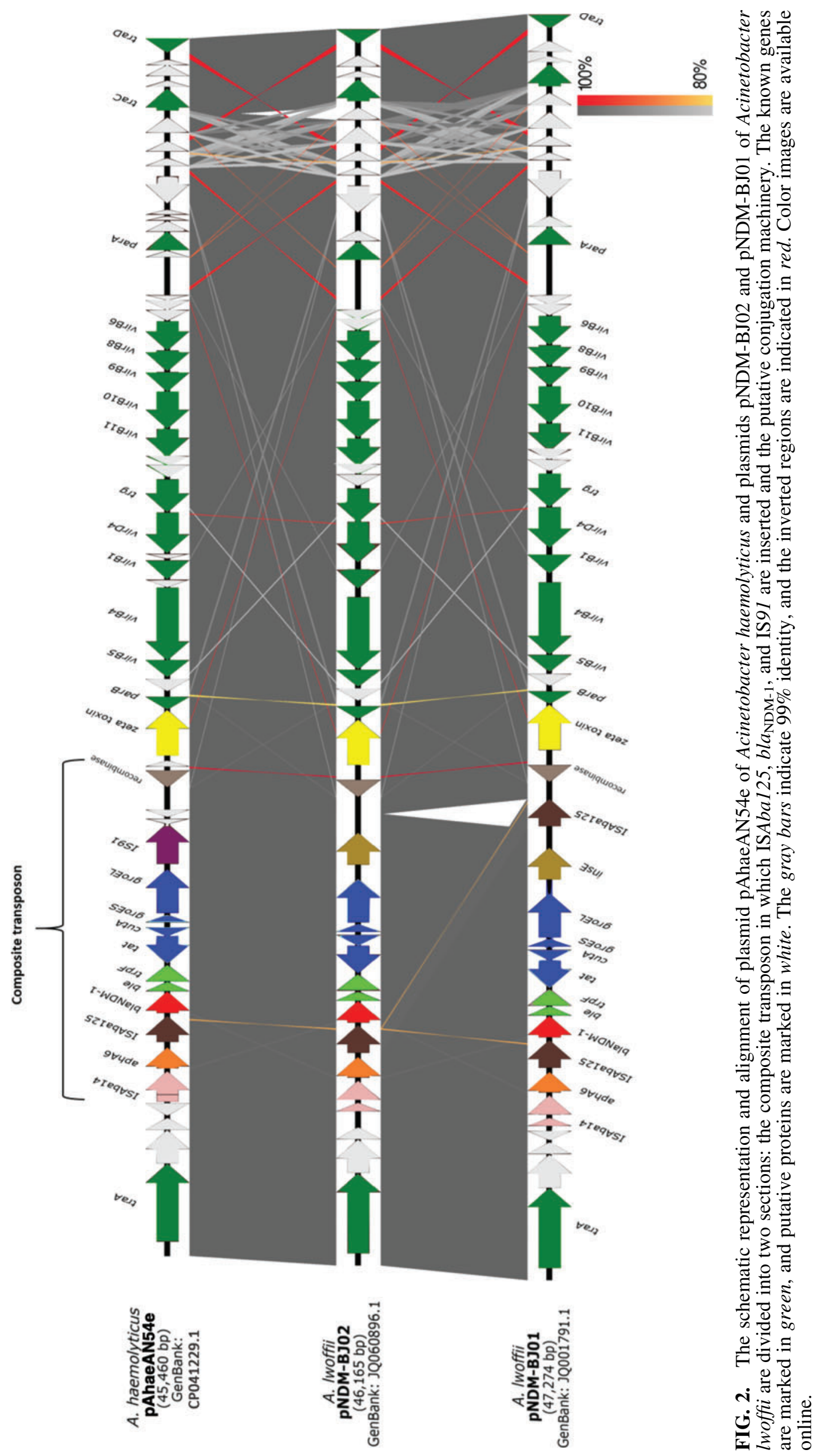




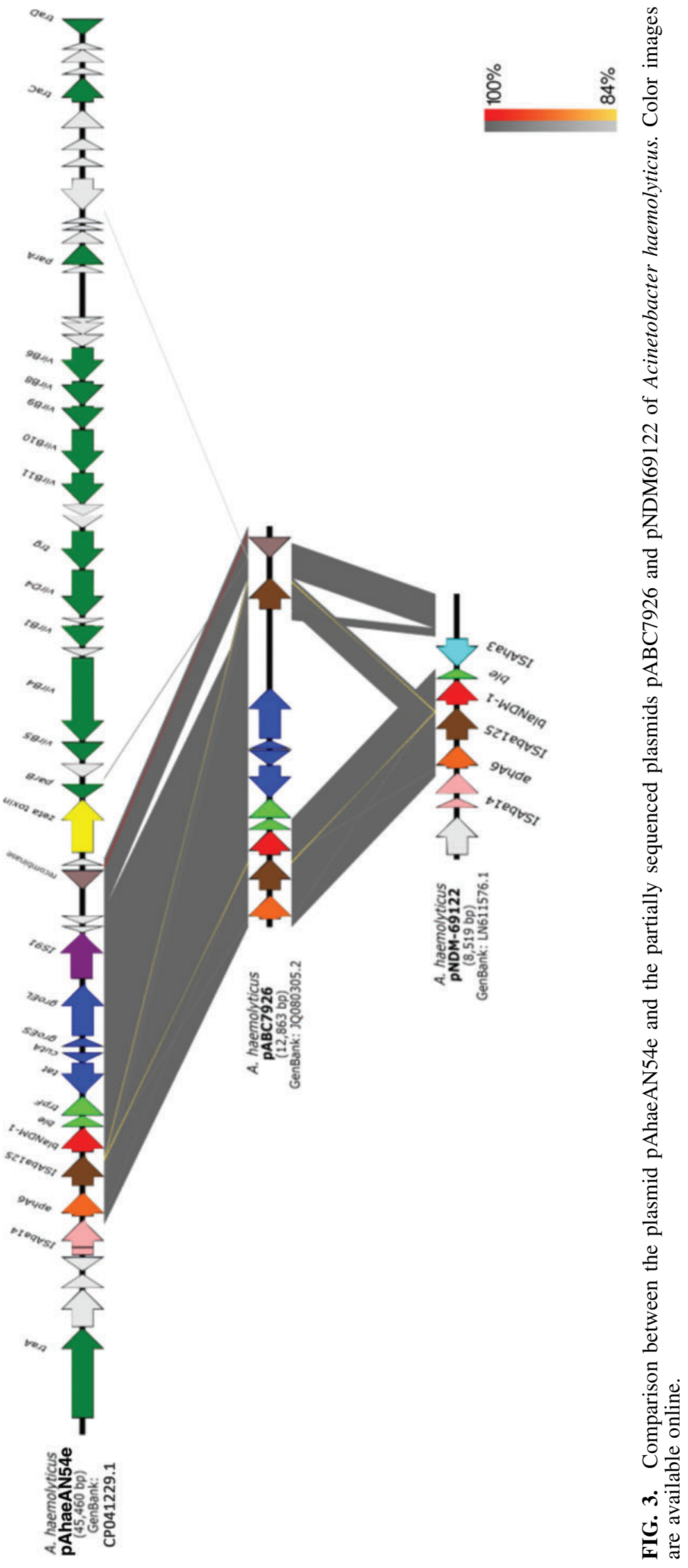




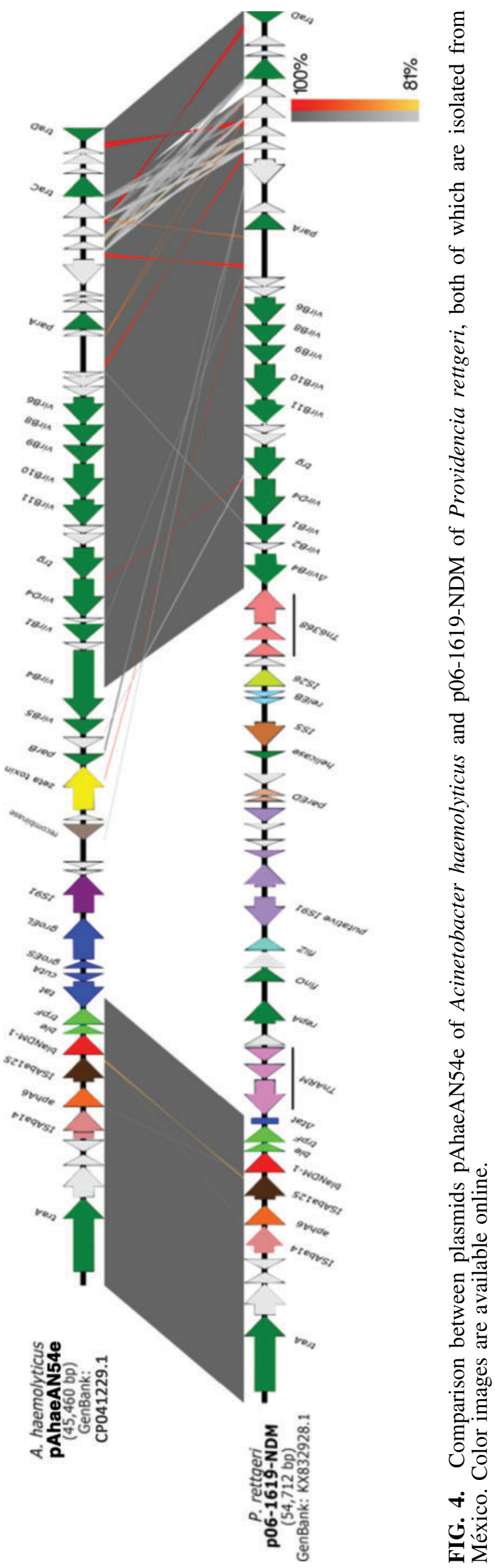

transference, as reported in other studies of Acinetobacter spp. carrying $b l a_{\mathrm{NDM}-1} \cdot{ }^{14,15,38,48}$

Recently, Duran-Bedolla et $a l .{ }^{17}$ partially reported the genetic context of bla $a_{\mathrm{NDM}-1}$ in strains of Acinetobacter spp., including the Acinetobacter haemolyticus 10256 strain isolated in a different geographical area of Mexico. The plasmid reported in our work showed specific differences in comparison with the plasmid of Acinetobacter haemolyticus 10256 (55 kbp plasmid); these included size (45.4 kbp), absence of ISAba125 sequence in the $3^{\prime}$ end, presence of genes encoding hypothetical proteins along the structure of the plasmid, and IS91 instead of ISCR27. These results suggest that the genetic context of bla $_{\mathrm{NDM}-1}$ in A. haemolyticus is partially conserved. ${ }^{17,29,30}$

Our study shows that plasmid pAhaeAN54e has a high similarity with plasmid p06-1619-NDM of P. rettgeri and, as noted by Marquez-Ortiz et al., ${ }^{31}$ the similarities among pNDM-BJ01-like plasmids and plasmids of $P$. rettgeri may be the result of recombination events that lead to a chimeric plasmid that can be transmitted and replicated among Enterobacteriaceae and Acinetobacter isolates. ${ }^{49}$

\section{Concluding Remarks}

In this study, we report a multidrug-resistant clinical A. haemolyticus strain isolated from a pediatric patient carrying bla $_{\mathrm{NDM}-1}$ in a novel variant of pNDM-BJ01-like plasmids. This plasmid could constitute a dissemination mechanism of antimicrobial resistance genes among diverse bacterial species. The findings reported in this work contribute to providing information about the diverse mechanisms of resistance that can coexist in A. haemolyticus strains.

\section{Acknowledgments}

The authors thank Liliana López-Pliego, PhD and Ángeles Pérez-Oseguera, MS for technical support in the laboratory. This work was funded by Benemérita Universidad Autonóma de Puebla, VIEP grant numbers: LOZP-NAT17-I and VIEP/2497/16 and partially supported by "Programa de Apoyo a Proyectos de Investigación e Innovación Tecnológica PAPIIT" (IN200318). Bello-López and CastroJaimes received Doctoral fellowships from CONACyT México with numbers: 273320 and 606188, respectively.

\section{Ethical Statement}

Acinetobacter haemolyticus AN54 isolate was collected during routine sampling, and patient data were anonymized. The protocol for this study was approved by the Ethical Committee of Hospital number: HNP/ENS/177/2016.

\section{Disclosure Statement}

No competing financial interests exist.

\section{References}

1. Peleg, A.Y., A. de Breij, M.D. Adams, G.M. Cerqueira, S. Mocali, M. Galardini, P.H. Nibbering, A.M. Earl, D.V. Ward, D.L. Paterson, H. Seifert, and L. Dijkshoorn. 2012. The success of Acinetobacter species; genetic, metabolic and virulence attributes. PLoS One. 7:e46984. 
2. Touchon, M., J. Cury, E.-J. Yoon, L. Krizova, G.C. Cerqueira, C. Murphy, M. Feldgarden, J. Wortman, D. Clermont, T. Lambert, C. Grillot-Courvalin, A. Nemec, P. Courvalin, and E.P.C. Rocha. 2014. The genomic diversification of the whole Acinetobacter genus: origins, mechanisms, and consequences. Genome Biol. Evol. 6: 2866-2882.

3. Wong, D., T.B. Nielsen, R.A. Bonomo, P. Pantapalangkoor, B. Luna, and B. Spellberg. 2017. Clinical and pathophysiological overview of Acinetobacter infections: a century of challenges. Clin. Microbiol. Rev. 30:409-447.

4. Esterly, J., C.L. Richardson, N.S. Eltoukhy, C. Qi, and M.H. Scheetz. 2011. Genetic mechanisms of antimicrobial resistance of Acinetobacter baumannii. Ann. Pharmacother. 45:218-228.

5. Traglia, G.M., M. Almuzara, E. Vilacoba, A. Tuduri, G. Neumann, E. Pallone, D. Centrón, and M.S. Ramírez. 2014. Bacteremia caused by an Acinetobacter junii strain harboring class 1 integron and diverse DNA mobile elements. J. Infect. Dev. Ctries. 8:666-669.

6. Rumbo, C., E. Gato, M. López, C. Ruiz de Alegría, F. Fernández-Cuenca, L. Martínez-Martínez, J. Vila, J. Pachón, J.M. Cisneros, J. Rodríguez-Baño, A. Pascual, G. Bou, and M. Tomás. 2013. Contribution of efflux pumps, porins, and $\beta$-lactamases to multidrug resistance in clinical isolates of Acinetobacter baumannii. Antimicrob. Agents Chemother. 57:5247-5257.

7. Berrazeg, M., S.M. Diene, L. Medjahed, P. Parola, M. Drissi, D. Raoult, and J.M. Rolain. 2014. New Delhi Metallo-beta-lactamase around the world: An eReview using Google Maps. Euro. Surveill. 19:pii: 20809.

8. Shahid, M. 2011. Environmental dissemination of NDM-1: time to act sensibly. Lancet Infect. Dis. 11:334-335.

9. Roca, I., P. Espinal, X. Vila-Farrés, and J. Vila. 2012. The Acinetobacter baumannii oxymoron: commensal hospital Dweller turned pan-drug-resistant menace. Front. Microbiol. 3:148.

10. Robledo, I.E., E.E. Aquino, M.I. Santé, J.L. Santana, D.M. Otero, C.F. León, and G.J. Vázquez. 2010. Detection of KPC in Acinetobacter spp. in Puerto Rico. Antimicrob. Agents Chemother. 54:1354-1357.

11. Pasteran, F., E. Albornoz, D. Faccone, S. Gomez, C. Valenzuela, M. Morales, P. Estrada, L. Valenzuela, J. Matheu, L. Guerriero, E. Arbizu, Y. Calderon, P. Ramon-Pardo, and A. Corso. 2012. Emergence of NDM-1-producing Klebsiella pneumoniae in Guatemala. J. Antimicrob. Chemother. 67:1795-1797.

12. Torres-González, P., M. Bobadilla-Del Valle, E. TovarCalderón, F. Leal-Vega, A. Hernández-Cruz, A. MartínezGamboa, M.D. Niembro-Ortega, J. Sifuentes-Osornio, and A. Ponce-de-León. 2015. Outbreak caused by Enterobacteriaceae harboring NDM- 1 metallo- $\beta$-lactamase carried in an IncFII plasmid in a tertiary care hospital in Mexico City. Antimicrob. Agents Chemother. 59:7080-7083.

13. Carvalho-Assef, A.P.D., P.S. Pereira, R.M. Albano, G.C. Beriao, T.P.G. Chagas, L.N. Timm, R.C.F. Da Silva, D.R. Falci, and M.D. Asensi. 2013. Isolation of NDM-producing Providencia rettgeri in Brazil. J. Antimicrob. Chemother. 68:2956-2957.

14. Pasteran, F., M.M. Mora, E. Albornoz, D. Faccone, R. Franco, J. Ortellado, N. Melgarejo, S. Gomez, I. Riquelme, J. Matheu, P. Ramon-Pardo, and A. Corso. 2014. Emergence of genetically unrelated NDM-1-producing Acineto- bacter pittii strains in Paraguay. J. Antimicrob. Chemother. 69:2575-2578.

15. Brovedan, M., P.M. Marchiaro, J. Morán-Barrio, M. Cameranesi, G. Cera, M. Rinaudo, A.M. Viale, and A.S. Limansky. 2015. Complete sequence of a $b l a_{(\mathrm{NDM}-1)^{-}}$ harboring plasmid in an Acinetobacter bereziniae clinical strain isolated in Argentina. Antimicrob. Agents Chemother. 59:6667-6669.

16. Pillonetto, M., L. Arend, E.C. Vespero, M. Pelisson, T.P.G. Chagas, A.P.D. Carvalho-Assef, and M.D. Asensi. 2014. First report of NDM-1-producing Acinetobacter baumannii sequence type 25 in Brazil. Antimicrob. Agents Chemother. 58:7592-7594.

17. Duran-Bedolla J., P. Bocanegra-Ibarias, J. Silva-Sánchez, E. Garza-González, R. Morfín-Otero, R. Hernández-Castro, L. Lozano, U. Garza-Ramos, and H. Barrios-Camacho. 2018. Genetic characterization of multiple NDM-1producing clinical isolates in Mexico. Diagn. Microbiol. Infect. Dis. 94:195-198.

18. Gundi, V.A., L. Dijkshoorn, S. Burignat, D. Raoult, and B. La Scola. 2009. Validation of partial rpoB gene sequence analysis for the identification of clinically important and emerging Acinetobacter species. Microbiology. 155:23332341.

19. La Scola, B., V.A.K.B. Gundi, A. Khamis, and D. Raoult. 2006. Sequencing of the $r p o B$ gene and flanking spacers for molecular identification of Acinetobacter species. J. Clin. Microbiol. 44:827-832.

20. Clinical Laboratory Standards Institute. 2017. Performance Standards for Antimicrobial Susceptibility Testing. Clinical and Laboratory Standards Institute, Wayne, PA.

21. Bonnin, R.A., T. Naas, L. Poirel, and P. Nordmann. 2012. Phenotypic, biochemical, and molecular techniques for detection of metallo- $\beta$-lactamase NDM in Acinetobacter baumannii. J. Clin. Microbiol. 50:1419-1421.

22. López-García, A., R.C. Rocha-Gracia, E. Bello-López, C. Juárez-Zelocualtecalt, Y. Sáenz, M. Castañeda-Lucio, L. López-Pliego, M.C. González-Vázquez, C. Torres, T. Ayala-Nuñez, G. Jiménez-Flores, M.M. de la Paz ArenasHernández, and P. Lozano-Zarain. 2018. Characterization of antimicrobial resistance mechanisms in carbapenemresistant Pseudomonas aeruginosa carrying IMP variants recovered from a Mexican hospital. Infect. Drug Resist. 11: 1523-1536.

23. Wick, R.R., L.M. Judd, C.L. Gorrie, and K.E. Holt. 2017. Unicycler: resolving bacterial genome assemblies from short and long sequencing reads. PLoS Comput. Biol. 13: e1005595.

24. Bankevich, A., S. Nurk, D. Antipov, A.A. Gurevich, M. Dvorkin, A.S. Kulikov, V.M. Lesin, S.I. Nikolenko, S. Pham, A.D. Prjibelski, A.V. Pyshkin, A.V. Sirotkin, N. Vyahhi, G. Tesler, M.A. Alekseyev, and P.A. Pevzner. 2012. SPAdes: a new genome assembly algorithm and its applications to single-cell sequencing. J. Comput. Biol. 19: 455-477.

25. Zankari, E., H. Hasman, S. Cosentino, M. Vestergaard, S. Rasmussen, O. Lund, F.M. Aarestrup, and M.V. Larsen. 2012. Identification of acquired antimicrobial resistance genes. J. Antimicrob. Chemother. 67:2640-2644.

26. Darling, A.C.E., B. Mau, F.R. Blattner, and N.T. Perna. 2004. Mauve: multiple alignment of conserved genomic sequence with rearrangements. Genome Res. 14:13941403. 
27. Sullivan, M.J., N.K. Petty, and S.A. Beatson. 2011. Easyfig: a genome comparison visualizer. Bioinformatics. 27:10091010.

28. Hu, H., Y. Hu, Y. Pan, H. Liang, H. Wang, X. Wang, Q. Hao, X. Yang, X. Yang, X. Xiao, C. Luan, Y. Yang, Y. Cui, R. Yang, G.F. Gao, Y. Song, and B. Zhu. 2012. Novel Plasmid and its variant haboring both a $b l a_{\mathrm{NDM}-1}$ gene and type IV secretion System in clinical isolates of Acinetobacrer lwoffii. Antimicrob. Agents Chemother. 56:16981702.

29. Jones, L.S., M.J. Carvalho, M.A. Toleman, P.L. White, T.R. Connor, A. Mushtaq, J.L. Weeks, K.K. Kumarasamy, K.E. Raven, M.E. Török, S.J. Peacock, R.A. Howe, and T.R. Walsh. 2015. Characterization of plasmids in extensively drug-resistant Acinetobacter strains isolated in India and Pakistan. Antimicrob. Agents Chemother. 59:923-929.

30. Fu, Y., L. Liu, X. Li, Y. Chen, Y. Jiang, Y. Wang, Y. Yu, and X. Xie. 2015. Spread of a common bla $a_{\mathrm{NDM}-1 \text {-carrying }}$ plasmid among diverse Acinetobacter species. Infect. Genet. Evol. 32:30-33.

31. Marquez-Ortiz, R.A., L. Haggerty, N. Olarte, C. Duarte, U. Garza-Ramos, J. Silva-Sanchez, B.E. Castro, E.M. Sim, M. Beltran, M.V. Moncada, A. Valderrama, J.E. Castellanos, I.G. Charles, N. Vanegas, J. Escobar-Perez, and N.K. Petty. 2017. Genomic epidemiology of NDM-1-encoding plasmids in Latin American clinical isolates reveals insights into the evolution of multidrug resistance. Genome Biol. Evol. 9:1725-1741.

32. Bocanegra-Ibarias, P., C. Peña-López, A. Camacho-Ortiz, J. Llaca-Díaz, J. Silva-Sánchez, H. Barrios, U. GarzaRamos, A.M. Rodríguez-Flores, and E. Garza-González. 2015. Genetic characterisation of drug resistance and clonal dynamics of Acinetobacter baumannii in a hospital setting in Mexico. Int. J. Antimicrob. Agents. 45:309-313.

33. Garza-González, E., J.M. Llaca-Díaz, F.J. Bosques-Padilla, and G.M. González. 2010. Prevalence of multidrugresistant bacteria at a tertiary-care teaching hospital in Mexico: Special focus on Acinetobacter baumannii. Chemotherapy. 56:275-279.

34. Morfín-Otero, R., M.D. Alcántar-Curiel, M.J. Rocha, C.M. Alpuche-Aranda, J.I. Santos-Preciado, C. GayossoVázquez, J.R. Araiza-Navarro, M. Flores-Vaca, S. EsparzaAhumada, E. González-Díaz, H.R. Pérez-Gómez, and E. Rodríguez-Noriega. 2013. Acinetobacter baumannii infections in a tertiary care hospital in mexico over the past 13 years. Chemotherapy. 59:57-65.

35. Figueiredo, S., R.A. Bonnin, L. Poirel, J. Duranteau, and P. Nordmann. 2012. Identification of the naturally occurring genes encoding carbapenem-hydrolysing oxacillinases from Acinetobacter haemolyticus, Acinetobacter johnsonii, and Acinetobacter calcoaceticus. Clin. Microbiol. Infect. 18:907-913.

36. Doi, Y., J.-I. Wachino, K. Yamane, N. Shibata, T. Yagi, K. Shibayama, H. Kato, and Y. Arakawa. 2004. Spread of novel aminoglycoside resistance gene aac(6')-Iad among Acinetobacter clinical isolates in Japan. Antimicrob. Agents Chemother. 48:2075-2080.

37. Lambert, T., G. Gerbaud, M. Galimand, and P. Courvalin. 1993. Characterization of Acinetobacter haemolyticus aac(6')-Ig gene encoding an aminoglycoside 6'-Nacetyltransferase which modifies amikacin. Antimicrob. Agents Chemother. 37:2093-2100.

38. Fu, Y., X. Du, J. Ji, Y. Chen, Y. Jiang, and Y. Yu. 2012. Epidemiological characteristics and genetic structure of bla $_{\mathrm{NDM}-1}$ in non-baumannii Acinetobacter spp. in China. J. Antimicrob. Chemother. 67:2114-2122.

39. Chu, Y.W., S.L. Chau, and E.T.S. Houang. 2006. Presence of active efflux systems AdeABC, AdeDE and AdeXYZ in different Acinetobacter genomic DNA groups. J. Med. Microbiol. 55:477-478.

40. Gholami, M., A. Hashemi, M. Hakemi-Vala, H. Goudarzi, and M. Hallajzadeh. 2015. Efflux pump inhibitor phenylalanine-arginine B-naphthylamide effect on the minimum inhibitory concentration of imipenem in Acinetobacter baumannii strains isolated from hospitalized patients in Shahid Motahari Burn Hospital, Tehran, Iran. Jundishapur. J. Microbiol. 8:e19048.

41. Wieczorek, P., P. Sacha, T. Hauschild, M. Zórawski, M. Krawczyk, and E. Tryniszewska. 2008. Multidrug resistant Acinetobacter baumannii-the role of AdeABC (RND family) efflux pump in resistance to antibiotics. Folia Histochem. Cytobiol. 46:257-267.

42. Damier-Piolle, L., S. Magnet, S. Brémont, T. Lambert, and P. Courvalin. 2008. AdeIJK, a resistance-nodulation-cell division pump effluxing multiple antibiotics in Acinetobacter baumannii. Antimicrob. Agents Chemother. 52:557562.

43. Coyne, S., G. Guigon, P. Courvalin, and B. Périchon. 2010. Screening and quantification of the expression of antibiotic resistance genes in Acinetobacter baumannii with a microarray. Antimicrob. Agents Chemother. 54:333-340.

44. Al Atrouni, A., M.-L. Joly-Guillou, M. Hamze, and M. Kempf. 2016. Reservoirs of Non-baumannii Acinetobacter Species. Front. Microbiol. 7:49.

45. Nordmann, P., L. Poirel, T.R. Walsh, and D.M. Livermore. 2011. The emerging NDM carbapenemases. Trends Microbiol. 19:588-595.

46. Toleman, M.A., P.M. Bennett, and T.R. Walsh. 2006. ISCR elements: novel gene-capturing systems of the 21 st century? Microbiol. Mol. Biol. Rev. 70:296-316.

47. Toleman, M.A., and T.R. Walsh. 2010. ISCR elements are key players in IncA/C plasmid evolution. Antimicrob. Agents Chemother. 54:3534.

48. Montaña, S., R. Cittadini, M. Del Castillo, S. Uong, T. Lazzaro, M. Almuzara, C. Barberis, C. Vay, and M.S. Ramírez. 2016. Presence of New Delhi metallo- $\beta$ lactamase gene (NDM-1) in a clinical isolate of Acinetobacter junii in Argentina. New Microbes New Infect. 11: 43-44.

49. Barrios, H., U. Garza-Ramos, F. Reyna-Flores, A. SanchezPerez, T. Rojas-Moreno, E. Garza-Gonzalez, J.M. Llaca-Diaz, A. Camacho-Ortiz, S. Guzman-Lopez, and J. Silva-Sanchez. 2013. Isolation of carbapenem-resistant NDM-1-positive Providencia rettgeri in Mexico. J. Antimicrob. Chemother. 68:1934-1936.

Address correspondence to:

Patricia Lozano-Zarain, PhD

Centro de Investigaciones de Ciencias Microbiológicas Instituto de Ciencias

Benemérita Universidad Autónoma de Puebla Edificio IC-11, Ciudad Universitaria Colonia Jardines de San Manuel Puebla, Pue. CP. 72570

México

E-mail: plozano_zarain@hotmail.com 